\title{
Monkey pod odununda yüzey pürüzlülüğü parametrelerinin ve shore-D sertlik değerinin belirlenmesi
}

\author{
Osman Çamlıbel $^{1}$ (D), Ümit Ayata*2 (DD
}

$\ddot{\mathbf{O z}}$

Yabancı tür ağaçlarından birisi olan monkey pod (Pithecellobium saman (Jacq.) Benth.), sert ve ağır bir yapıya sahip olup, ahşabı döşeme, kalıp yapımı, tornalama, dolap yapımı, mobilya, yer döşemesi, panel ve cephe kaplaması olarak kullanılmaktadır. Bu çalışmada, monkey pod odununda farklı numaralara $(80,100,120,150,180$ ve 220) sahip zimparaların kullanılması ile elde edilen yüzeyler üzerinde yüzey pürüzlülügü parametreleri ve shore - D sertlik değeri belirlenmiştir. Elde edilen testlere ait sonuçlar bazı ağaç türleri ile kıyaslanmıştır. Araştırma sonuçlara göre, monkey pod odununda shore - D sertlik değeri 71.70 olarak belirlenmiştir. Buna ek olarak, zımparalama işlemlerinden sonra zımpara numarasının artması ile yüzey pürüzlülüğü parametrelerine $\left(R_{\mathrm{a}}, R_{\mathrm{z}}\right.$ ve $\left.R_{\mathrm{q}}\right)$ ait sonuçların azaldığ 1 belirlenmiştir. Zımparalama işleminden sonra, $R_{\text {a }}$ parametresi 80 no'lu zımpara için $6.462 \mu \mathrm{m}, 100$ no'lu zımpara için $5.473 \mu \mathrm{m}, 120$ no'lu zımpara için $4.521 \mu \mathrm{m}, 150$ no'lu zımpara için $3.761 \mu \mathrm{m}, 180$ no'lu zımpara için $2.681 \mu \mathrm{m}$ ve 220 no'lu zımpara için $1.883 \mu \mathrm{m}$ olarak elde edilmiştir.

Anahtar kelimeler: Zımparalama, Shore - D, yüzey pürüzlülügüü, Monkey pod, Pithecellobium saman,

\section{Determination of surface roughness parameters and shore - D hardness value in monkey pod wood}

\begin{abstract}
Monkey pod (Pithecellobium saman (Jacq.) Benth.), one of the foreign species trees, has a hard and heavy structure and is used as flooring, mold making, turning, cabinet making, furniture, flooring, panel and facade coating. In this study, surface roughness parameters and shore - D hardness value were determined on the surfaces obtained by using sandpaper with different numbers $(80,100,120,150,180$ and 220) in monkey pod wood. The results of the obtained tests compared with some tree species. According to the results of the research, shore-D hardness value in monkey pod wood was determined as 71.70. In addition to this, it was determined that the results of the surface roughness parameters $\left(R_{\mathrm{a}}, R_{\mathrm{Z}}\right.$ and $\left.R_{\mathrm{q}}\right)$ decreased with the increase of the sanding number after the sanding processes. After sanding, the $R_{\mathrm{a}}$ parameter is $6.462 \mu \mathrm{m}$ for sanding no $80,5.473 \mu \mathrm{m}$ for sanding no $100,4.521 \mu \mathrm{m}$ for sanding no $120,3.761 \mu \mathrm{m}$ for sanding no $150,2.681 \mu \mathrm{m}$ for sandpaper no. and $1.883 \mu \mathrm{m}$ for sandpaper no. 220 .
\end{abstract}

Keywords: Sanding, Shore - D, surface roughness, Monkey pod, Pithecellobium saman, 


\section{Giriș}

Monkey pod (Pithecellobium saman (Jacq.) Benth.) ağaç türü, Asya, Afrika, Kuzey Amerika, Güney Amerika, Orta Amerika ve Karayipler'de geniş bir dağılıma sahiptir (Staples ve Elevitch 2006). Kosta Rika'nın doğal yaprak döken ormanında nehir kenarı bir türdür (Janzen 1982).

Fabaceae familyasındaki çiçekli ağaç türüdür ve genellikle "yağmur ağacı", "maymun kabuğu", "cow tamarind", Sanskritçe'de "Shiriisha", Tamil'de "Thoogumoonji maram" ve Malayalam'da “Chakaravaraty maram" olarak adlandırılır (Janzen 1982).

Yaprak dökmeyen bir ağaç olarak kabul edilir. Ancak şiddetli kuraklık dönemlerinde yaprak döken olabilir (Janzen 1982). Şemsiye şeklindeki barınak gibi özellikleriyle kolayca tanınır. Açıkta yetiştirilir ve genellikle 15-25 m yüksekliğe ulaşır (Kabir ve ark., 2012). Küçük çiftliklerde ve parklarda ve geçitte yol kenarındaki alanlarda gölge ağacı olarak Pasifik’teki en önemli bitkilerden biridir (Muthuchelian ve ark., 2003).

Genellikle gölge ve süs ağacı olarak dikilmektedir (Anonim 1979). Ekildiğinde çok çeşitli topraklarda iyi olarak büyüyebilmekte ve mevsimsel sellere dayanabilmektedir (Webb ve ark., 1980). Niktinastik yaprak hareketleri çalışmaları için uzun zamandır bitki fizyologlarının favorisi olmuştur (Satter ve ark., 1981).

Hawaii'de yılın herhangi bir zamanında çiçek açabilir, ancak genellikle Nisan'dan Ağustos'a kadar çiçek açar ve çiçeklenme zirvesi Mayıs'tır. Çiçekler kusursuz ve şemsiye şeklindedir. Çiçekler böcekle tozlanır. Tohum kabukları 6 ila 8 ayda gelişir. Hawaii'de genellikle Aralık ve Nisan ayları arasında, bozulmadan yere düşer (Rock 1920, Little ve Wadsworth 1964). Tohumları ilkbaharda düşer ve yaklaşık 1 ay sonra açılır. Yaklaşık 4 ayda fideler büyümeye başlar (Skolmen 1983).

Serbestçe süzülen topraklarda büyür ve engellenmiş drenajı artırır. Bazı durumlarda kısa süreler için suyla tıkanmış toprakları tolere edebilir. Mangrovların hemen iç kesimlerinde, hafif yüksek bir arazide büyüdüğü bilinmektedir (Francis 2004). Tropikal ortamda yetiştirilir (Muthuchelian ve ark., 2003).

Odunundan oyulmuş kâseler, zanaat odunu ve yakacak odun kullanımı sınırlıdır (Muthuchelian ve ark., 2003). Ahşabı, oymacılıkta ve mobilya yapımında oldukça değerlidir (Anonim 1979). Kanolar, bölünmüş direkler ve ahşap aletler ve mutfak eşyaları, dolap yapımı, mobilya, yer döşemesi, panel ve cephe kaplaması için kullanılır. Tekne yapımında döşeme, döşeme ve ağır çerçeve elemanları olarak kullanılmıştır (Skolmen 1974).

Asya'nın başka yerlerinde saman, müzik aletleri yapmak için kullanılır. Kosta Rika'da, geleneksel kağnı arabalarının tekerlekleri, büyük gövdelerinin enine kesitlerinden yapıldığ bildirilmiştir (Record ve Hess 1943). Venezuela' da lamine kirişler için kullanılmıştır. Çerçeve yapımı, kalıp yapımı, tornalama ve küçük işçilik için kullanıldığı (Longwood 1962), odunu sert ve ağır (Streets 1962) olup, işlenmesinin zor (Longwood 1961, Little ve Wadsworth 1964) olduğu bildirilmiştir.

Öz odunu çürümeye ve böceklere karşı dayanıklıdır (Wolcott 1946). Yaprakları ve kabukları, yüksek besleyici içeriği ve azot bağlama kabiliyeti nedeniyle besin olarak kullanılır (Muthuchelian ve ark., 2003).

Meyvesi baklagildir ve baklalar meyankökü benzeri tatlı bir meyve özü içerir, yenilebilir, kahverengimsi, tatlı aromalı hamur ve bu hamurdan limonata benzeri bir içecek yapılır (Staples ve Elevitch 2006). 
$\mathrm{Bu}$ çalışmada, monkey pod odununda zımparalama sonucu elde edilen yüzeylerdeki yüzey pürüzlülüğü ve shore - D sertlik değerleri belirlenmiştir. Literatürde Monkey pod ağaç türüne ait çeşitli zımpara tipleri ile zımparalanan yüzeylerdeki yüzey pürüzlülüğü değerlerine ve shore - D sert sertlik değerlerine ait çalışma bulunmamaktadır. Mobilya sektöründe kullanılan bu ağaç türüne ait belirlenmiş olan çalışma sonuçlarının, başta mobilya sektörü alanına ve monkey pod ağacına ait literatüre önemli bilgiler sağlayacağı düşünülmektedir.

\section{Materyal ve Metot}

\subsection{Materyal}

Çalışmada, monkey pod (Pithecellobium saman (Jacq.) Benth.) ağaç türüne ait keresteler Mersin'de bulunan bir ticari kereste şirketinden satın alma yöntemi ile $15 \mathrm{x} 15 \mathrm{x}$ $100 \mathrm{~cm}$ boyutlarında olacak şekilde temin edilmiştir. Malzemeler üzerinde iklimlendirme işlemleri $\left(20 \pm 2^{\circ} \mathrm{C}\right.$ ve $\% 65$ bağıl nem şartları) yapılmıştır (ISO 554, 1976).

\subsection{Metot}

\subsubsection{Yüzey pürüzlülüğü özelliklerinin belirlenmesi}

100 x 100 × 9 mm boyutlarındaki örneklere 80,100,120,150, 180 ve 220 no'lu zımparalar el ile uygulanmıştır. Yüzey pürüzlülük parametrelerine ait $\left(R_{\mathrm{a}}, R_{\mathrm{z}}\right.$ ve $\left.R_{\mathrm{q}}\right)$ ölçümler JTKY JD - 520 model (Çin) pürüzlülük test cihazında (ISO 16610-21, 2011) liflere dik yönde, örnek uzunluğu $2.5 \mathrm{~mm}$ ve örnek uzunluk sayısı (cut - off) 5 olacak şekilde yapılmıştır.

\subsubsection{Shore - D sertlik özelliklerinin belirlenmesi}

Shore - D sertlik değerleri (Stand: model Ld-J Loyka, Çin ve Durometer: Çin) 5 kg'llk yük uygulamalı olacak şekilde ASTM D 2240 (2010)'a göre 30 ölçüm alınarak yapılmıştır.

\section{3. İstatistiksel analiz}

Bir SPSS programinda standart sapma, homojenlik grubu, ortalama, minimum ve maksimum değerleri ve varyasyon katsayıları hesaplanmıştır.

\section{Bulgular ve Tartışma}

Shore - D sertlik testine ait sonucu Çizelge 1'de verilmiştir. Shore - D sertlik değeri 71.70 olarak tespit edilmiş olunup, 70.00 - 73.00 arasında değiştiği görülmektedir.

Çizelge 1. Shore - D sertlik testine ait sonuç

\begin{tabular}{llllll}
\hline Ölçüm Sayısı & Ortalama & Standart Sapma & Minimum & Maksimum & Varyasyon Katsayısı \\
\hline $\mathbf{3 0}$ & 71.70 & 0.99 & 70.00 & 73.00 & 1.38 \\
\hline
\end{tabular}

Bazı ağaç türlerinde belirlenmiş olan shore - D sertlik değerleri Çizelge 2'de verilmiştir. Monkey pod odunun shore - D sertlik sonucunun Çizelge 2'de verilen bütün ağaçlardan yüksek olduğu görülmektedir. Şanıvar ve Zorlu (1980)'ya göre yapılan açıklamada, sertlik değerinin ağaçtan ağaca büyük farklılıklar göstermektedir. 
Çizelge 2. Bazı ağaç türlerinde belirlenmiş olan shore - D sertlik değerleri

\begin{tabular}{|c|c|c|}
\hline Ăgaç Türü & Shore - D & Kaynak \\
\hline Ak kavak (Populus alba L.) & 31.50 & Akçay (2020) \\
\hline Ayous (Triplochiton scleroxylon K. Schum.) & 37.65 & Ayata (2020) \\
\hline Sarıçam (Pinus sylvestris L.) & 39.20 & Akçay (2020) \\
\hline Simul (Salmalia malabarica) & 40.00 & Devi ve Maji (2012) \\
\hline Ihlamur (Tilia grandifolia Ehrh.) & 40.40 & Akçay (2020) \\
\hline Kavak (Populus spp.) diri odun & 42.35 & Li ve ark., (2018) \\
\hline Loblolly (Pinus taeda) çamı & 42.60 & Mattos ve ark., (2015) \\
\hline Kavak (Populus spp.) & 43.52 & Dong ve ark., (2015) \\
\hline İncir (Ficus hispida) & 45.00 & Hazarika ve Maji (2013) \\
\hline Amerikan titrek kavağ1 (Populus tomentosa Carr.) & 46.35 & Yan ve ark., (2015) \\
\hline Kauçuk ağacı (Hevea brasiliensis) & 46.57 & Devi ve ark., (2003) \\
\hline Pinus sp. & 48.40 & Dos Santos ve ark., (2019) \\
\hline Beijing kavağ1 (Populus beijingensis W. Y. Hsu) & 51.80 & Chu ve ark., (2016) \\
\hline Huş (Betula pendula L.) & 52.60 & Ayata ve Bal (2020b) \\
\hline Doğu kayını (Fagus orientalis L.) & 52.80 & Akçay (2020) \\
\hline Monkey pod (Pithecellobium saman (Jacq.) Benth.) & $\mathbf{7 1 . 7 0}$ & Tespit \\
\hline Yalancı akasya (Robinia pseudoacacia L.) & 79.35 & Ayata ve Bal (2020c) \\
\hline
\end{tabular}

Yüzey pürüzlülük parametrelerine ait sonuçları Çizelge 3'de verilmiştir. Çizelge 3'e göre, zımpara numarasının artması ile yüzey pürüzlülüğ̈̈ parametrelerine $\left(R_{\mathrm{a}}, R_{\mathrm{z}}\right.$ ve $\left.R_{\mathrm{q}}\right)$ ait sonuçların azaldığı görülmektedir.

Çizelge 3. Yüzey pürüzlülük parametrelerine ait sonuçları

\begin{tabular}{|c|c|c|c|c|c|c|c|c|}
\hline $\begin{array}{l}\text { Para- } \\
\text { metre }\end{array}$ & $\begin{array}{l}\text { Zimpara } \\
\text { Numarası }\end{array}$ & $\begin{array}{l}\text { Ölçüm } \\
\text { Sayısı }\end{array}$ & $\begin{array}{c}\text { Ortalama } \\
(\mu \mathrm{m})\end{array}$ & $\begin{array}{l}\text { Standart } \\
\text { Sapma }\end{array}$ & $H G$ & Minimum & Maksimum & $\mathrm{COV}$ \\
\hline \multirow{6}{*}{$\boldsymbol{R}_{\mathbf{a}}$} & 80 & 10 & 6.462 & 0.30 & $\mathrm{~A}^{*}$ & 6.111 & 7.116 & 4.62 \\
\hline & 100 & 10 & 5.473 & 0.11 & $\mathrm{~B}$ & 5.336 & 5.671 & 1.96 \\
\hline & 120 & 10 & 4.521 & 0.38 & $\mathrm{C}$ & 4.129 & 4.916 & 8.35 \\
\hline & 150 & 10 & 3.761 & 0.16 & $\mathrm{D}$ & 3.447 & 3.916 & 4.36 \\
\hline & 180 & 10 & 2.681 & 0.10 & $\mathrm{E}$ & 2.544 & 2.784 & 3.55 \\
\hline & 220 & 10 & 1.883 & 0.08 & $\mathrm{~F}$ & 1.707 & 1.992 & 4.27 \\
\hline \multirow{6}{*}{$\boldsymbol{R}_{\mathbf{q}}$} & 80 & 10 & 8.450 & 0.32 & $\mathrm{~A}^{*}$ & 8.136 & 9.121 & 3.82 \\
\hline & 100 & 10 & 7.507 & 0.21 & $\mathrm{~B}$ & 7.237 & 7.940 & 2.77 \\
\hline & 120 & 10 & 6.297 & 0.38 & $\mathrm{C}$ & 5.909 & 6.765 & 6.06 \\
\hline & 150 & 10 & 5.494 & 0.28 & $\mathrm{D}$ & 5.215 & 5.962 & 5.02 \\
\hline & 180 & 10 & 4.228 & 0.16 & $E$ & 4.034 & 4.501 & 3.71 \\
\hline & 220 & 10 & 3.257 & 0.17 & $\mathrm{~F}$ & 3.049 & 3.470 & 5.30 \\
\hline \multirow{6}{*}{$\boldsymbol{R}_{\mathbf{z}}$} & 80 & 10 & 44.372 & 2.57 & $\mathrm{~A}^{*}$ & 41.751 & 49.359 & 5.78 \\
\hline & 100 & 10 & 42.048 & 1.82 & $\mathrm{~B}$ & 40.099 & 45.149 & 4.34 \\
\hline & 120 & 10 & 38.181 & 1.52 & $\mathrm{C}$ & 36.329 & 40.702 & 3.99 \\
\hline & 150 & 10 & 32.837 & 2.53 & $\mathrm{D}$ & 29.958 & 36.310 & 7.71 \\
\hline & 180 & 10 & 27.786 & 0.61 & $E$ & 27.118 & 28.920 & 2.18 \\
\hline & 220 & 10 & 22.913 & 1.13 & $\mathrm{~F}$ & 21.929 & 25.021 & 4.92 \\
\hline
\end{tabular}

$H G$ : Homojenlik Grubu, COV: Varyasyon Katsayısı, *: En yüksek değeri ifade etmektedir.

Çizelge 4'de bazı ağaç türleri ile monkey pod ağaç türüne ait yüzey pürüzlülüğü $\left(R_{\mathrm{a}}\right.$, $R_{\mathrm{z}}$ ve $R_{\mathrm{q}}$ ) değerlerinin kıyaslanması verilmiştir. Literatürde limon, Malta eriği, tiama (Ayata ve Bal 2020a), huş (Ayata ve Bal 2020b), ayous (Ayata 2020), maun (Ayata ve Bal 2019a), sapsız meşe (Ayata ve Bal 2019b), Amerikan ceviz (Ayata ve Bal 2019c), kızılağaç (Ayata ve Bal 2019d), dibétou (Ayata ve Bal 2019e) ve dabema (Ayata ve Bal 2019f) ağaç türlerine uygulanmış olan farklı zımpara numaralarına sahip zımparalarda zımpara numarasının artması 
ile pürüzlülük parametrelerinin azaldığı görülmektedir. Elde edilen sonuçlar literatür ile uyumlu olduğunu göstermektedir (Çizelge 4).

Çizelge 4. Bazı ağaç türlerinde yüzey pürüzlülüğü değerlerinin kıyaslanması $(\mu \mathrm{m})$

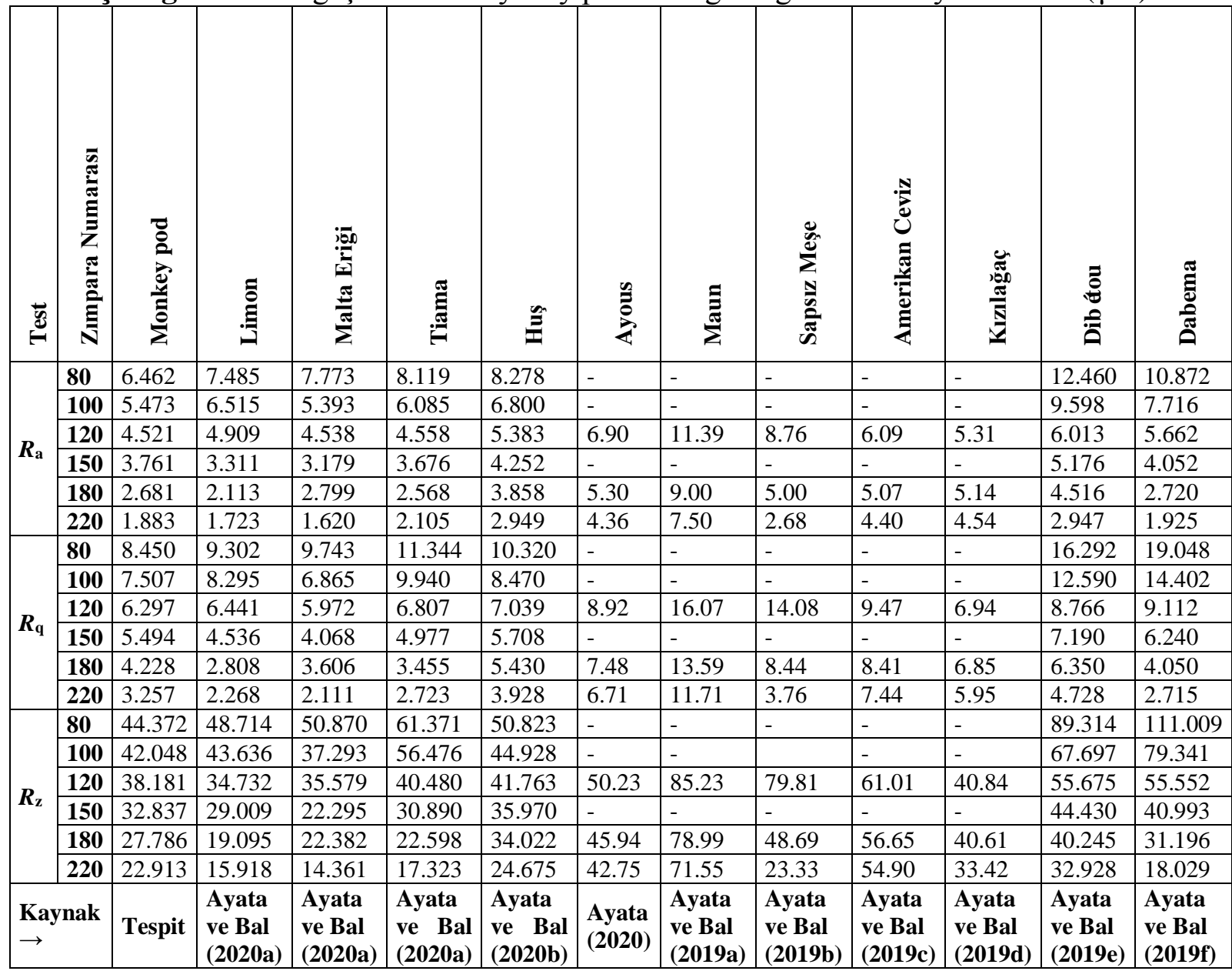

\section{Sonuçlar ve Öneriler}

Bu araştırmada, monkey pod (Pithecellobium saman (Jacq.) Benth.) odun türünde shore - D sertlik değeri ve yüzey pürüzlülügü parametreleri belirlenmiş olunup, aşağıdaki sonuçlara ulaşılmıştır:

- Shore - D sertlik değeri 71.70 olarak elde edilmiştir,

- Zımparalama işlemlerinden sonra zımpara numarasının artması ile yüzey pürüzlülüğü parametrelerine $\left(R_{\mathrm{a}}, R_{\mathrm{Z}}\right.$ ve $\left.R_{\mathrm{q}}\right)$ ait sonuçların azaldığı belirlenmiştir. Zımpralama uygulamasından sonra, $R_{\mathrm{a}} 80$ no'lu zımpara için $6.462 \mu \mathrm{m}, 100$ no'lu zımpara için 5.473 $\mu \mathrm{m}, 120$ no'lu zımpara için $4.521 \mu \mathrm{m}, 150$ no'lu zımpara için $3.761 \mu \mathrm{m}, 180$ no'lu zımpara için $2.681 \mu \mathrm{m}$ ve 220 no'lu zımpara için $1.883 \mu \mathrm{m}$ elde edilmiştir.

Yurt dışında mobilya sektöründe kullanılan monkey pod ağaç türünde çeşitli vernik türlerinin ve hatta UV sistem parke verniğinin uygulanması önerilmekte olunup, elde edilen malzeme üzerinde parlaklık, renk, salınımsal sertlik, çizilme, kurşun kalem testi, yüzeye yapışma direnci, vb. testlerin yapılması ile uygulanacak olan vernik kimyasalları ile arasındaki ilişkinin belirlenmesi ve ayrıca ahşabına ait mekanik, fiziksel ve kimyasal özelliklerinin araştırılması önerilmektedir. 


\section{Kaynaklar}

Akçay, Ç., (2020), Determination of decay, larvae resistance, water uptake, color, and hardness properties of wood impregnated with honeybee wax, BioResources, 15(4): 8339-8354. DOI: 10.15376/biores.15.4.8339-8354.

Anonim, (1979), Tropical legumes-resources for the future, Report of the Ad Hoc Panel of the Advisory Committee on Technology Innovation, National Academy of Sciences, Washington, DC. 332 p.

ASTM D 2240, (2010), Standard test method for rubber property-durometer hardness, American Society for Testing and Materials, West Conshohocken, Pennsylvania, United States.

Ayata, Ü., (2020), Ayous odununun bazı teknolojik özelliklerinin belirlenmesi ve 1s1 işlemden sonra renk ve parlaklık özellikleri, Mobilya ve Ahşap Malzeme Araştırmaları Dergisi, 3(1): 22-33. DOI: 10.33725/mamad.724596.

Ayata, Ü., ve Bal, B.C., (2019a), Maun (Swietenia mahagoni L.) odununda yüzey pürüzlülüğü üzerine zımparalama ve planyanın etkisi, Avrasya 4. Uluslararası Uygulamalı Bilimler Kongresi, 27-29 Eylül, Kiev, Ukrayna, 19-22.

Ayata, Ü., ve Bal, B.C., (2019b), Sapsız meşe (Quercus petreae L.) odununda statik sertlik tayini ve yüzey pürüzlülügü parametreleri, ISPEC 2. Uluslararası Tarım Ve Kırsal Kalkınma Kongresi, 27-29 Eylül, Kiev, Ukrayna, 22-28.

Ayata, Ü., ve Bal, B.C., (2019c), Amerikan ceviz odununda yüzey pürüzlülüğü, janka sertlik değeri ve çivi tutma direncinin belirlenmesi, Çukurova 3. Uluslararası Yenilikçi Bilimsel Araştırmalar Kongresi, 3-6 Ekim, Adana, Türkiye, 440-448.

Ayata, Ü., ve Bal, B.C., (2019d), Kızılağaç odununda statik sertlik, yüzey pürüzlülüğü ve çivi tutma direncinin belirlenmesi, III. Uluslararası Akdeniz Orman ve Çevre Sempozyumu, 3-5 Ekim, Kahramanmaraş, Türkiye, 921-926.

Ayata, Ü., ve Bal, B.C., (2019e), Dibétou odununda yüzey pürüzlülüğü parametrelerinin araştırılması, Avrasya 5. Uluslararası Uygulamalı Bilimler Kongresi, 15-17 Kasım, Adana, Türkiye, 646-651.

Ayata, Ü., ve Bal, B.C., (2019f), Dabema (Piptadeniastrum africanum Brenan) odununda bazı yüzey özelliklerinin belirlenmesi, Ziraat, Orman ve $\mathrm{Su}$ Ürünleri Alanında Araştırma Makaleleri, Gece Kitaplığı Yayınevi, Ankara, Türkiye, Genel Yayın Yönetmeni: Atilla ATİK, Editörler: İsmet DAŞDEMİR, Hüseyin Atilla ATİK, 16 Aralık 2019, 252-266. Matbaa Sertifika No: 42539, Yayıncı Sertifika No: 15476, ISBN: 978-625-7958-10-3.

Ayata, Ü., ve Bal, B.C., (2020a), Tiama, limon ve malta eriği odunlarının zımparalanmasında zımpara tanecik büyüklügünün yüzey pürüzlülüğüne etkisi, Ziraat, Orman ve $\mathrm{Su}$ Ürünleri Alanında Teori ve Araştırmalar, Gece Kitaplığı Yayınevi, Ankara, Türkiye, Genel Yayın Yönetmeni: Eda Altunel, Editör: Nigar Yarpuz BOZDOĞAN, 19 Eylül 2020, 65-81. ISBN: 978-625-7243-66-7.

Ayata, Ü., ve Bal, B.C., (2020b), Huş odununun yüzey pürüzlülüğü, çivi tutma direnci ve shore - D sertlik değerinin belirlenmesi, $4^{\text {th }}$ Asia Pacific International Modern, 12- 13 December 2020 Subic Bay Freeport Zone, Philippines, Sciences Congress, 611-622.

Ayata, Ü., ve Bal, B.C., (2020c), Yalanc1 akasya (Robinia pseudoacacia L.) odununda baz1 fiziksel ve mekanik özelliklerinin belirlenmesi, Ziraat, Orman ve Su Ürünleri Alanında 
Teori ve Araştırmalar II, Gece Kitaplığı Yayınevi, Ankara, Türkiye, Editör: Prof. Dr. Koray ÖZRENK, Aralık 2020, 199-216.

Chu, D., Xue, L., Zhang, Y., Kang, L., and Mu, J., (2016), Surface characteristics of poplar wood with high-temperature heat treatment: Wettability and surface brittleness, BioResources, 11(3): 6948-6967. DOI: 10.15376/biores.11.3.6948-6967.

Devi, R.R., Ali, I., and Maji, T.K., (2003), Chemical modification of rubber wood with styrene in combination with a crosslinker: effect on dimensional stability and strength property, Bioresource Technology, 88: 185-188. DOI: 10.1016/S0960-8524(03)0003-8.

Devi, R.R., and Maji, T.K., (2012), Chemical modification of simul wood with styreneacrylonitrile copolymer and organically modified nanoclay, Wood Science and Technology, 46: 299-315. DOI 10.1007/s00226-011-0406-2.

Dong, Y., Yan, Y., Zhang, S., Li, J., and Wang, J., (2015), Flammability and physicalmechanical properties assessment of wood treated with furfuryl alcohol and nano- $\mathrm{SiO}_{2}$, European Journal of Wood and Wood Products, 73: 457-464. DOI: 10.1007/s00107015-0896-y.

Dos Santos, P.S.B., Erdocia, X., Gatto, D.A., and Labidi, J., (2016), Bio-oil from basecatalyzed depolymerization of organosolv lignin as an antifungal agent for wood, Wood Science and Technology, 50(3): 599-615. DOI: 10.1007/s00226-015-0795-8.

Francis, J.K., (2004), USDA Forest Service Research Forester (re-tired), Personal communication, July 2004.

Hansson, L., and Antti, A.L., (2006). The effect of drying method and temperature level on the hardness of wood, Journal of Materials Processing Technology, 171(3): 467-470. DOI: $10.1016 /$ j.jmatprotec.2005.08.007.

Hazarika, A., and Maji, T.K., (2013), Effect of different crosslinkers on properties of melamine formaldehyde-furfuryl alcohol copolymer/montmorillonite impregnated softwood (Ficus hispida), Polymer Engineering and Science, 53: 1394-1404. DOI: 10.1002/pen.23391.

ISO 16610-21, (2011), Geometrical Product Specifications (GPS) - Filtration - Part 21: Linear Profile Filters: Gaussian Filters, Standard.

ISO 554, (1976), Standard Atmospheres for Conditioning and/or Testing - Specifications, International Organization for Standardization.

Janzen, D.H., (1982), Cenizero tree (Legumlnosae: Pithece/Iobium saman) delayed fruit development in Costa Rican deciduous forests, Journal of Botany. 69(8): 1269-1276.

Kabir, M., Iqbal, Z.M., and Shafiq, M., (2012), Traffic density, climatic conditions and seasonal growth of Samanea saman (Jacq.) Merr. on different polluted roads of Karachi City, Pakistan Journal of Botany, 44(6): 1881-90.14.

Li, J., Zhang, A., Zhang, S., Gao, Q., Chen, H., Zhang, W., and Li, J., (2018), Highperformance imitation precious wood from low-cost poplar wood via high-rate permeability of phenolic resins, Polymer Composites, 39(7): 2431-3440. DOI: $10.1002 / p c .24226$.

Little, E.L., Jr., and Wadsworth, F.H., (1964), Common trees of Puerto Rico and the Virain Islands, U.S. Department of Agriculture, Agriculture - Handbook Washington, DC. 548. 
Longwood, F., (1961), Puerto Rican woods: machining, seasoning and related characteristics, Department of Agriculture, Agriculture Handbook Washington, DC, 98 p.

Longwood, F., (1962), Present and potential commercial timbers of the Caribbean, Agric. Handb. 207. Washington, DC: US. Department of Agriculture, 171 p.

Mattos, B.D., Cademartori, P.H.G., Missio, A.L., Gatto, D.A., and Magalhaes, W.L.E., (2015), Wood-polymer composites prepared by free radicalin situ polymerization of methacrylate monomersinto fast-growing pinewood, Wood Science and Technology, 49: 1281-1294. DOI: 10.1007/s00226-015-0761-5.

Muthuchelian, K., Meenakshi, V., and Nedunchezhian, N., (2003), Protective effect of triacontanol against acidic mists in Samanea saman (Jacq.) Merrill seedlings: Differential responses in growth, $14 \mathrm{CO}_{2}$ fixation, ribulose-1,5-bisphosphate carboxylase, and electron transport activities, Photosynthetic, 41(3): 335-341.

Record, S., and Hess, R., (1943), Timbers of the new World, New Haven, CT: Yale University Press. 640 p.

Rock, J.F., (1920), Leguminous trees of Hawaii, Honolulu, Hawaiian Sugar Planters' Association Experiment Station, Honolulu, 234 p.

Satter, R.L., Guggino, S.E., Lonergan, T.A., and Galston, A.W., (1981), The effects of blue and far red light onrhythmic leaf let movements in Samanea (saman) and Albizzia (julibrissin), Plant Physiology, 67(5): 965-968.

Skolmen, R., (1974), Some woods of Hawaii properties and uses of 16 commercial species, Gen. Tech. Rep. PSW-8. Berkeley, CA: US. Department of Agriculture, Forest Service, Pacific Southwest Forest and Range Experiment Station; 30 p.

Skolmen, R., (1983), Raintree, saman, monkey-pod, Tropical Tree Note 2, American Pacific Forestry News, 1 p.

Staples, G.W., and Elevitch, C.R., (2006), Samanea saman (rain tree) ver. 2.1. in Elevitch CR (ed.). Special Profile for Pacific Island Agroforestry, Permanent Agricultural Resources (PAR), Holualoa, Hawaii.

Streets, H.F., (1962), Exotic forest trees in the British Commonwealth, Clarendon Press, Oxford, $765 \mathrm{p}$.

Şanıvar, N., ve Zorlu, İ., (1980), Ağaç işleri gereç bilgisi temel ders kitabı, Mesleki Ve Teknik Öğretim Kitapları, Milli Eğitim Basımevi, İstanbul, Etüd ve Programlama Dairesi Yayınları No: 43, 472 sayfa.

Webb, D.B., Wood, P.J., and Smith, J.A., (1980), A guide to species selection for tropical and sub-tropical plantations, Commonwealth Forestry Institute, Tropical Forestry Paper 15, Overseas Development Association, London, 342 p.

Wolcott, G.N., (1946), A list of woods arranged according to their resistance to the attack of the West - Indian dry - wood termite Cryptotermes brevis. Caribbean Journal, 7(4): 329-334.

Yan, Y., Dong, Y., Li, J., Zhang, S., Xia, C., Shi, S.Q., and Cai, L., (2015), Enhancement of mechanical and thermal properties of poplar through the treatment of glyoxalurea/nano-SiO 2 , Royal Society of Chemistry Advances, 5(67): 54148-54155. DOI: 10.1039/C5RA07294H. 